Research paper

\title{
Utilisation of diesel engine waste heat by Organic Rankine Cycle
}

\author{
Benedikt Kölsch, Jovana Radulovic \\ School of Engineering, University of Portsmouth, Anglesea Road, PO1 3DJ Portsmouth, Hampshire, UK
}

\section{H I G H L I G H T S}

- ORC powered by diesel-engine waste heat was developed.

- Methanol, Toluene and Solkatherm were considered as working fluids.

- Methanol was selected due to the best overall thermal performance.

- Optimal cycle operating parameters and heat exchanger area were evaluated.

\section{A R T I C L E I N F O}

\section{Article history:}

Received 8 September 2014

Accepted 1 January 2015

Available online 9 January 2015

\section{Keywords:}

Organic Rankine Cycle

Diesel engine waste heat

Heat exchanger

Thermal efficiency

Net power output
G R A P H I C A L A B S T R A C T

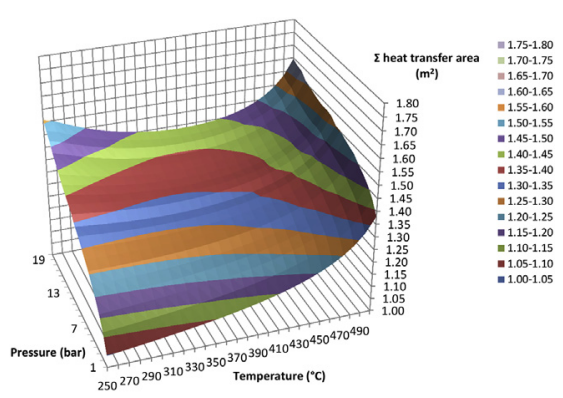

\begin{abstract}
A B S T R A C T
In this paper, three different organic liquids were investigated as potential working fluids in an Organic Rankine Cycle. Performance of Methanol, Toluene and Solkatherm SES36 was modelled in an ORC powered by a diesel engine waste heat. The ORC model consists of a preheater, evaporator, superheater, turbine, pump and two condensers. With variable maximum cycle temperatures and high cycle pressures, the thermal efficiency, net power output and overall heat transfer area have been evaluated.

Methanol was found to have the best thermal performance, but also required the largest heat transfer area. While Toluene achieved lower thermal efficiency, it showed great work potential at high pressures and relatively low temperatures. Our model identified the risks associated with employing these fluids in an ORC: methanol condensing during the expansion and toluene not sufficiently superheated at the turbine inlet, which can compromise the cycle operation. The best compromise between the size of heat exchanger and thermodynamic performance was found for Methanol ORC at intermediate temperatures and high pressures. Flammability and toxicity, however, remain the obstacles for safe implementation of both fluids in ORC systems.
\end{abstract}

๑) 2015 Elsevier Ltd. All rights reserved.

\section{Introduction}

Prevention of environmental pollution and the development of innovative, renewable and more efficient resources are the imperatives of the modern society. The internal combustion engine is the most common type of car engine and with the prospect of

\footnotetext{
* Corresponding author.

E-mail address: jovana.radulovic@port.ac.uk (J. Radulovic).
}

continuing to be so in the future, it is essential to continue developing this engine-type, primarily through increase in efficiency and reduction in fuel consumption. Our aim was to contribute towards a solution for pollution reduction and improved performance of internal combustion engines by coupling it with an additional element that harnesses the waste heat and contributes towards the higher overall efficiency.

Roughly one third of the energy which is generated from an engine is converted to mechanical power; the remaining energy is released in form of heat [1]. Thus, the challenge of reaching thermal 


\begin{tabular}{|c|c|c|c|}
\hline \multicolumn{2}{|c|}{ Nomenclature } & $\eta_{\text {th }}$ & thermal efficiency \\
\hline & & $\eta_{\mathrm{T}}$ & turbine efficiency \\
\hline A & heat transfer area $\left(\mathrm{m}^{2}\right)$ & $\eta_{\mathrm{P}}$ & pump efficiency \\
\hline$c_{p}$ & specific heat capacity (kJ/kg K) & $\mu$ & dynamic viscosity (Pa s) \\
\hline $\mathrm{D}$ & diameter of heat exchanger (m) & $\rho$ & density $\left(\mathrm{kg} / \mathrm{m}^{3}\right)$ \\
\hline $\mathrm{F}$ & reynolds number & $\sigma$ & surface tension $(\mathrm{N} / \mathrm{m})$ \\
\hline h & specific enthalpy (kJ/kg) & $X$ & Lockhard-Martinelli Parameter \\
\hline $\mathrm{h}_{\mathrm{LG}}$ & latent heat of vaporisation $(\mathrm{kJ} / \mathrm{kg})$ & & \\
\hline ICE & Internal Combustion Engine & \multicolumn{2}{|c|}{ Subscripts } \\
\hline $\mathrm{k}$ & thermal conductivity $(\mathrm{W} / \mathrm{mK})$ & 1 & turbine inlet \\
\hline $\mathrm{k}_{\mathrm{e}}$ & Eötvös constant $\left(\mathrm{J} / \mathrm{Kmol}^{2 / 3}\right)$ & 2 & turbine outlet \\
\hline $\mathrm{L}$ & heat exchanger length (m) & 3 & pump inlet \\
\hline LMTD & log mean temperature difference & $3 a$ & condenser 1 inlet \\
\hline M & molar mass $(\mathrm{kg} / \mathrm{mol})$ & 4 & pump outlet/Preheater inlet \\
\hline$\dot{m}$ & mass flow rate $(\mathrm{kg} / \mathrm{s})$ & 5 & preheater outlet/Evaporator inlet \\
\hline $\mathrm{Nu}$ & Nusselt number & 6 & evaporator outlet/Superheater inlet \\
\hline ORC & Organic Rankine Cycle & $\mathrm{b}$ & boiling \\
\hline $\mathrm{P}$ & pressure (bar) & $\mathrm{cb}$ & convective boiling \\
\hline PP & pinch Point (K) & $\operatorname{con} 1$ & condenser 1 (two phase condenser) \\
\hline $\operatorname{Pr}$ & Prandtl number & $\operatorname{con} 2$ & condenser 2 (single phase condenser) \\
\hline$\dot{Q}$ & rate of heat flow $(\mathrm{kJ} / \mathrm{s})$ & evap & evaporator \\
\hline $\operatorname{Re}$ & Reynolds number & ex & exhaust \\
\hline$S$ & suppression factor & FZ & Forster and Zuber correlation \\
\hline S & specific entropy (kJ/kg K) & $\mathrm{g}$ & gas phase \\
\hline $\mathrm{T}$ & temperature $(\mathrm{K})$ & $\mathrm{i}$ & inside \\
\hline $\mathrm{T}_{\mathrm{c}}$ & critical temperature $(\mathrm{K})$ & in & inlet \\
\hline$\Delta \mathrm{T}$ & temperature difference $(\mathrm{K})$ & 1 & liquid phase \\
\hline$\Delta \mathrm{T}_{\mathrm{lm}}$ & log mean temperature difference $(\mathrm{K})$ & $\mathrm{m}$ & mean \\
\hline$U^{\prime m}$ & overall heat transfer coefficient $\left(\mathrm{W} / \mathrm{m}^{2} \mathrm{~K}\right)$ & $\mathrm{nb}$ & nucleate boiling \\
\hline & molar volume $\left(\mathrm{m}^{3} / \mathrm{mol}\right)$ & o & outside \\
\hline $\mathrm{W}_{\text {net }}$ & net power output (kW) & out & outlet \\
\hline \multirow{2}{*}{\multicolumn{2}{|c|}{$\mathrm{x} \quad$ vapour quality }} & preh & preheater \\
\hline & & sat & saturated \\
\hline \multicolumn{2}{|c|}{ Greek letters } & sup & superheater \\
\hline$\alpha$ & individual heat transfer coefficient $\left(\mathrm{W} / \mathrm{m}^{2} \mathrm{~K}\right)$ & tp & two phase \\
\hline
\end{tabular}

efficiency higher than $42 \%$ remains. If only $6 \%$ of the heat contained in exhaust gases would be converted to electrical power, the fuel consumption could be reduced by around $10 \%$. There are different systems of exhaust heat recovery, including mechanical and electrical turbocompounding, thermoelectric materials [2] or turbochargers [3]. This paper focuses on exhaust heat recovery using an Organic Rankine Cycle (ORC) system.

Utilisation of ORC in exhaust heat recovery is not a new concept [4]. General advantages of an ORC system are well suited for the application, including good flexibility and efficient utilisation of separate heat sources [5]. As the exhaust heat is converted to electrical power, the fuel consumption decreases and the overall engine efficiency increases. Thus, it could be considered as an environmental friendly solution. Problems could occur in terms of space limitations and the additional weight of the ORC system itself. Nevertheless, numerous studies proved significant improvement in total system efficiency if bottoming ORC recovery system is implemented. Different aspects of conversion of diesel engine waste heat into electricity have been studied ([6], and references therein). Yu et al. have studied performance of bottoming ORC under different engine conditions. Katsanos et al. [7] have considered both water and organic cycles applied on a diesel truck engine. They found favourable performance of the ORC yet emphasised that significantly higher mass flow rates were needed. Recently, Capata and Toro have analysed patented "on-board" ORC recovery system [8].
In spite of considerable scientific attention the discussion around the 'optimal' ORC working fluid continues [9]. In fluid selection suitable thermophysical properties of the organic fluid are the prerogative, yet chemical stability, toxicity and flammability must be considered. Many working fluids commonly considered for ORC application may have undesirable values of ODP and GWP, and these must be taken in account in the light of strict emission reduction legislations. Most studies agree the 'optimal' choice depends on the type of the heat source and on operational parameters, as well as on cycle configuration [10]. Therefore, the challenge to find a suitable fluid which has satisfying thermodynamic properties and is environmentally safe remains [11].

This paper discusses how the selection of different working fluids influences the efficiency and the net power output of an ORC exhaust heat recovery system. Thermodynamically different working fluids have been selected for the study, primarily assessing their suitability to be used in wide pressure and temperature range of operational parameters. The overall performance is discussed in terms of thermal efficiency and power produced, but also implications on heat exchanger size. The required heat transfer areas have been evaluated for promising performance scenarios.

\section{Working fluid selection}

Suitable working fluids for ORC can be segmented into different classes [12] and [13]. From the structural point of view and based on 
atomic composition of the fluid molecule, ORC fluids can be categorised in 7 classes, presented in Table 1.

Despite the variety of the working fluid studies, no single fluid has been identified as the optimal one for all ORC processes. The extent of fluid candidates varies widely and different types of heat sources and working conditions have to be considered when selecting the optimal working fluid. Furthermore, different performance indicators result in different choice of the best fluid [12]. We compared the performance of three different working fluids: Methanol, Toluene and Solkatherm SES36. Three dissimilar fluids were chosen: Methanol as a wet fluid, Toluene as a dry fluid, and Solkatherm as a mixture. Therefore, these fluids representing entirely different fluid types whose behaviour is thermodynamically dissimilar and should produce significantly contrasting results.

Methanol is a common ORC working fluid. Because of the negative slope in the $T-S$ diagram (Fig. 1 ) of its saturation vapour curve $(d s / d T<0)$ Methanol is a wet fluid. Wet fluids have a good overall performance in energy conversion efficiency, but the possible presence of liquid during the expansion process may damage the turbine blades. Thus, an implementation of a superheater is crucial. Furthermore, Methanol has flammability issues.

The second fluid selected for this study is Toluene. Toluene is an aromatic hydrocarbon and, unlike Methanol, it is a dry working fluid. Dry fluids have a positive slope of the saturation vapour curve $(d s / d T>0)$ in the $T-s$ diagram. For dry fluids there is no risk of condensation during the expansion in the turbine, so the superheating process is not as essential as for wet fluids. The thermodynamic properties of hydrocarbons are desirable, but toluene is still highly flammable.

The mixture Solkatherm SES36 is a composed of two fluids: the first fluid is 1,1,1,3,3-pentafluorobutane or R365mfc [14] with a percentage of $\approx 65 \%$. 1-Propene, 1,1,2,3,3,3-hexafluoro-, oxidised, polymd. or $\mathrm{CF}_{3} \mathrm{O}\left[\mathrm{CF}_{2} \mathrm{C}\left(\mathrm{CF}_{3}\right) \mathrm{FO}\right]_{n}\left(\mathrm{CF}_{2} \mathrm{O}\right)_{\mathrm{m}} \mathrm{CF}_{3}$ [15] is the second part of the mixture with a percentage of $\approx 35 \%$. Solkatherm developed to be mainly used in the heat transfer applications, but also as a refrigerant or solvent. Other properties of this mixture are that it is non-flammable, not toxic, colourless, and chemically and thermally stable up to $220^{\circ} \mathrm{C}$.

Apart from different shapes of the saturation curves (Fig. 1) selected fluids also have dissimilar critical point values, and are therefore categorised differently [9]. The main thermodynamic properties of selected fluids are presented in Table 2. Fluids have different range of applicability (chemical stability and decomposition limits) and impose certain flammability and toxicity risks;

Table 1

Classes of ORC fluids and their main properties.

\begin{tabular}{ll}
\hline Group & Fluid properties \\
\hline Hydrocarbons & - Desirable thermodynamic properties, but issues \\
& with flammability \\
Perfluorocarbons & - Aromatics more thermally stable than linear structures \\
Siloxanes & - Inert and stable, yet thermodynamically undesirable \\
& - Low toxicity and flammability \\
Ethers & - No corrosiveness, good lubricants \\
& - Flammability and toxicity issues, thermodynamically \\
Alcohols & - Undesirable \\
& - Common working fluids achieving good efficiencies \\
Partially fluoro- & - Slammable \\
substituted & Several low ODP fluids of potential interest \\
straight chain & \\
hydrocarbons & \\
Inorganics & - Extensive group with low environmental impact \\
& - Inexpensive \\
\hline
\end{tabular}

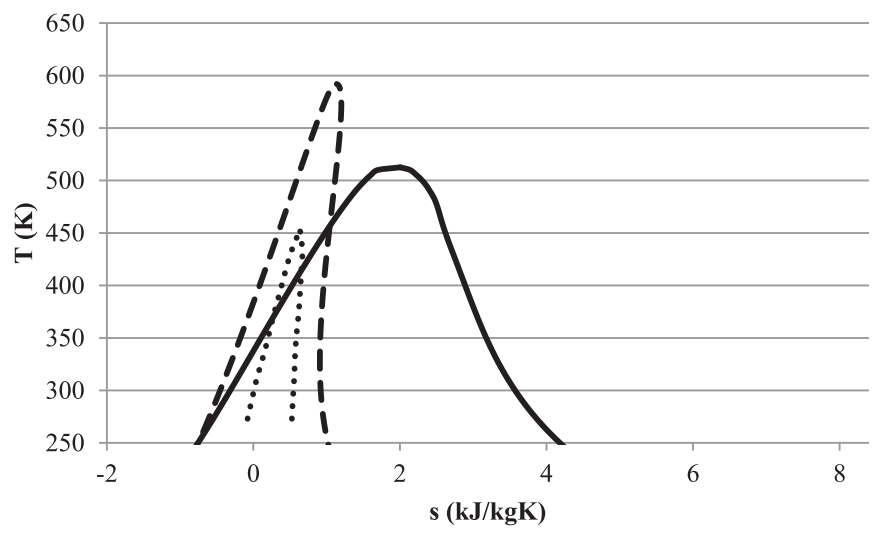

Fig. 1. T-s diagrams: Methanol (solid line); Toluene (dashed line); Solkatherm (dotted line).

however, working fluids with similar environmental impact and/or safety classification are increasingly being considered in ORC, with some already commercially employed.

Further differences in three ORCs studied are reflected in turbine size, which can be a limiting factor. Turbine design and operational requirements are quantified using turbine size parameter and isentropic volume flow ratio, which both strongly depend on the critical temperature of the working fluid [13]. Both parameters are quite variable and largely dependent on the working fluid considered. Methanol, and especially Toluene, due to relatively high critical temperatures, have values of both parameters outside the range conventionally selected for ORC. High critical temperature fluids are generally not considered in low temperature source cycles, as large size parameter and volume flow ratio values require oversized cycle components. However, these fluids have been shortlisted for several studies and turbine size obstacles can be alleviated via careful selection of cycle parameters, appropriate for the heat source considered $[10,16]$.

\section{Model}

\subsection{Diesel engine}

The selected diesel engine is a six cylinder, four stroke engine, whose main operational parameters are shown in Table 3 [17]. All values are assumed to be constant; starting and braking conditions which would affect the temperature and mass flow rate are disregarded. The ORC system which is driven by diesel engine exhaust heat consists mainly of turbine, generator, two condensers (condenser 1 and 2) for cooling the system, working fluid pump, preheater, evaporator, superheater and the internal combustion engine, as shown in Fig. 2.

Table 2

Thermodynamic properties of selected fluids.

\begin{tabular}{lccl}
\hline Property/Fluid & Methanol & Toluene & Solkatherm $^{\text {a }}$ \\
\hline Molar mass $(\mathrm{kg} / \mathrm{mol})$ & 32.042 & 92.138 & 184.5 \\
$\mathrm{~T}_{\mathrm{b}}\left({ }^{\circ} \mathrm{C}\right)$ & 64.48 & 110.6 & 35.6 \\
$\mathrm{~T}_{\mathrm{c}}\left({ }^{\circ} \mathrm{C}\right)$ & 239.45 & 318.6 & 177.6 \\
$\mathrm{P}_{\mathrm{c}}(\mathrm{bar})$ & 81.035 & 41.263 & 28.5 \\
$\mathrm{~T}_{\max }\left({ }^{\circ} \mathrm{C}\right)$ & 620 & 700 & $463-493$ \\
\hline
\end{tabular}

a According to manufacturer's specification: the first decomposition reactions occur in laboratory at $220^{\circ} \mathrm{C}$; it has been proved in continuous operation conditions up to $190^{\circ} \mathrm{C}$. 
Table 3

Diesel engine data sheet [2].

\begin{tabular}{ll} 
Electrical power output & $235.8 \mathrm{~kW}$ \\
Torque & $1500 \mathrm{Nm}$ \\
Exhaust temperature & $519{ }^{\circ} \mathrm{C} / 792.15 \mathrm{~K}$ \\
Rotate speed & $1501 \mathrm{rpm}$ \\
Fuel consumption & $47.79 \mathrm{~kg} / \mathrm{h}$ \\
Combustion air mass flow & $943 \mathrm{~kg} / \mathrm{h}(0.292 \mathrm{~kg} / \mathrm{s})$ \\
Exhaust gas mass flow & $990.79 \mathrm{~kg} / \mathrm{h}(0.275 \mathrm{~kg} / \mathrm{s})$ \\
Mixture composition & $\mathrm{CO}_{2}: 15.1 \%$ \\
& $\mathrm{H}_{2} \mathrm{O}: 5.37 \%$ \\
& $\mathrm{~N}_{2}: 73.04 \%$ \\
& $\mathrm{O}_{2}: 6.49 \%$ \\
\hline
\end{tabular}

\subsection{The model}

The basic processes of the Organic Rankine Cycle can be delineated as followed [18]: 1. Irreversible adiabatic expansion of steam in turbine (1-2); 2 . Isobaric cooling of the steam until saturation temperature (2-3a); 3. Isobaric cooling and steam condensation (3a-3); 4. Adiabatic pump pressure increase (3-4); 5. Isobaric fluid preheating by the exhaust steam (4-5); 6 . Isobaric fluid evaporation by the exhaust steam (5-6); 7. Isobaric fluid superheating by the exhaust steam (6-1). All progressions of temperature of the exhaust (red line, in the web version), the working fluid (here presented for Methanol - green line, in the web version) and the cooling fluid (blue line, in the web version) are presented on the $T-S$ diagram in Fig. 3.

\subsection{Assumptions}

Our ORC model is based on the following assumptions:

1. Methanol, Toluene and Solkatherm SES36 are chosen as working fluids for the ORC.

2. A steady-state steady-flow system is considered.
3. Kinetic and potential energy losses as well as heat losses in all components and pipes are neglected.

4. The only pressure drops are in the turbine and the pump.

5. The isentropic turbine efficiency $\left(\eta_{T}\right)$ is set to 0.7 and the isentropic pump efficiency $\left(\eta_{P}\right)$ is set to 0.8 [17].

6. The minimum pinch point is set to $\Delta T_{5}=30 \mathrm{~K}$ [19]. It is beneficial for the cycle performance to choose a small pinch point, as the net power output increases, which is an advantage, but the heat transfer area increases as well. Hence, the system gets heavier, the fuel consumption increases and the overall efficiency decreases.

7. Tube heat exchangers in preheater, evaporator, superheater and condensers are of an inner diameter $\left(D_{i}\right)$ of $0.013 \mathrm{~m}$ and an outer diameter $\left(D_{0}\right)$ of $0.018 \mathrm{~m}$.

8. Air is used as a cooling fluid, with an assumed temperature of $25{ }^{\circ} \mathrm{C}$ at point 3a. Hence, the fluid temperature is presumed to be $30{ }^{\circ} \mathrm{C}$ at this point with a pinch point of $5 \mathrm{~K}$. The condensing pressure was chosen based on $25^{\circ} \mathrm{C}$ saturation temperature.

9. Fouling inside the heat exchangers is neglected.

10. All fluids in the liquid phase are assumed to be incompressible.

\subsection{Thermal efficiency and net power}

Fluid properties at relevant points of the cycle were calculated by using the fluid database REFPROP [20]. The turbine inlet temperature (point 1) was initially estimated to be in the $150{ }^{\circ} \mathrm{C}-500^{\circ} \mathrm{C}$ range; the temperature range of Solkatherm limited to $220^{\circ} \mathrm{C}$. Isothermobar connecting points $3 \mathrm{a}$ and 3 was set at $30^{\circ} \mathrm{C}$. The evaporation line (5-6) is set at the maximum cycle pressure. The thermal efficiency of the cycle is:

$\eta_{\text {th }}=\frac{\left(h_{1}-h_{2}-h_{4}+h_{3}\right) \dot{m}}{\left(h_{1}-h_{4}\right) \dot{m}}=\frac{\dot{W}_{\text {out }}}{\dot{Q}_{\text {in }}}$

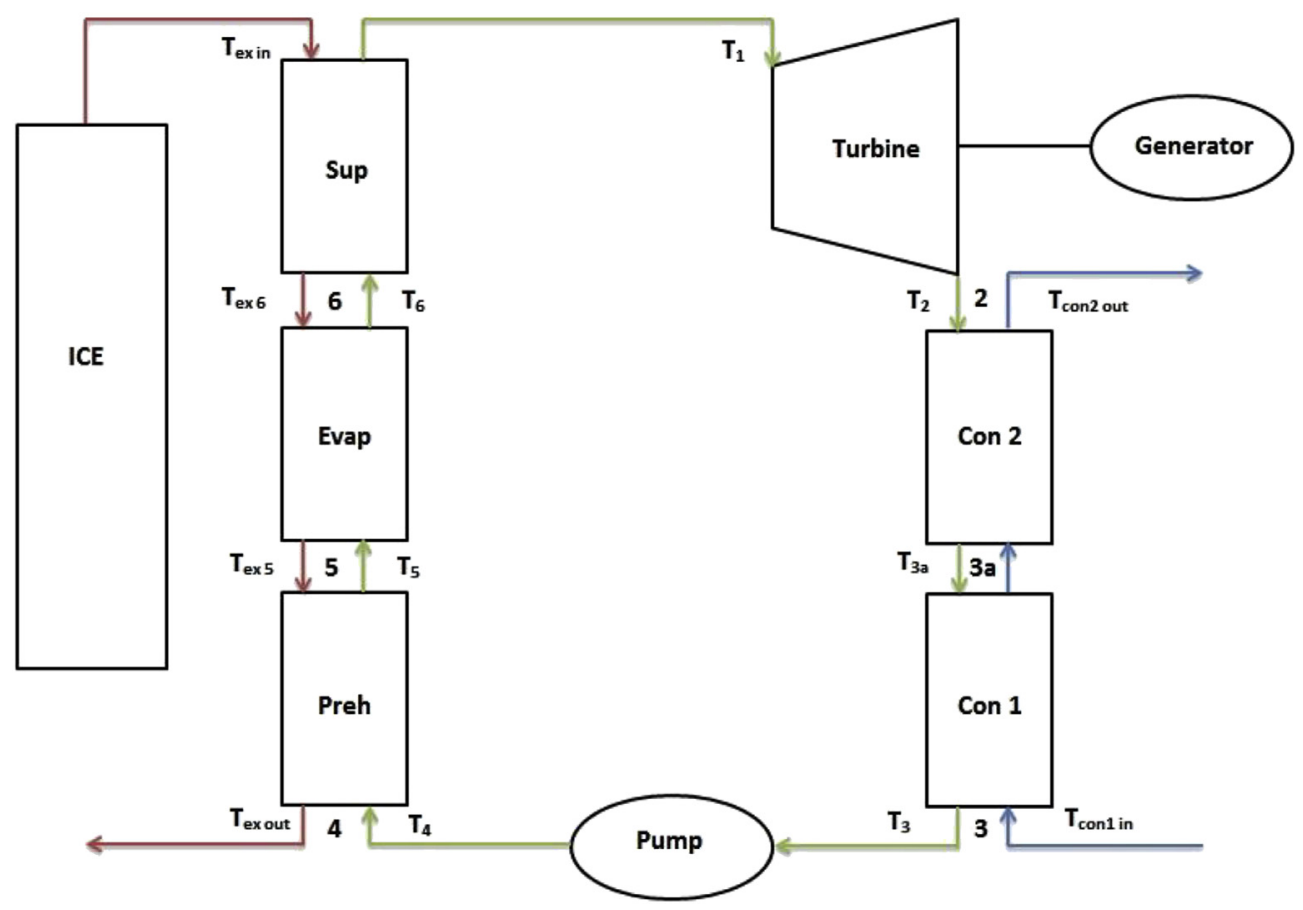

Fig. 2. Schematic model diagram of the ORC system. 
The exhaust temperature at the heat exchanger inlet, $T_{\text {ex }}$ in at point 1 , as specified in the engine data sheet, was modelled as $519{ }^{\circ} \mathrm{C}$. The exhaust temperate at point 5 can be estimated using pinch point temperature:

$T_{e x 5}=T_{5}+P P$

In our calculations we have used the provided exhaust gas mass flow rate, $m_{e x}$, of $0.275 \mathrm{~kg} / \mathrm{s}$ and the mean specific exhaust heat capacity, $c_{p}$ ex $m$, was calculated by REFPROP for the given exhaust gas composition. The mass flow rate of the fluid was calculated from the energy balance:

$\dot{m}=m_{e x} c_{p}$ ex $\frac{T_{\text {ex in }}-T_{\text {ex } 5}}{h_{1}-h_{5}}$

The actual net power output is:

$W_{\text {net }}=\left(h_{1}-h_{2}-h_{4}+h_{3}\right) \dot{m}=W_{T}-W_{P}$

\subsection{Heat exchanger}

The overall heat transfer coefficient was estimated in order to evaluate the required heat transfer area. The following energy balances were used to calculate exhaust temperature at point 6 and the exhaust outlet temperature:

$T_{\text {ex } 6}=T_{\text {ex in }}-\frac{\dot{m}\left(h_{1}-h_{6}\right)}{m_{e x} c_{p \text { ex } m}}$

$T_{\text {ex out }}=T_{\text {ex in }}-\frac{\dot{m}\left(h_{1}-h_{4}\right)}{\dot{m}_{\text {ex }} c_{p \text { ex } m}}$

The temperature differences between the exhaust and the working fluid are:

$\Delta T_{\text {in }}=T_{\text {ex } \text { in }}-T_{1}$
$\Delta T_{6}=T_{e x} 6-T_{6}$

$\Delta T_{\text {out }}=T_{\text {ex } \text { out }}-T_{4}$

\subsubsection{Exhaust}

The overall heat transfer coefficient depends on the individual heat transfer coefficients of the preheater, the evaporator or the superheater and the individual heat transfer coefficient of the exhaust gas.

Reynolds number for the exhaust flow:

$R e_{e x}=\frac{\rho u_{m} D_{h}}{\mu_{e x}}=\frac{4 m_{e x}}{\pi\left(D_{o}+D_{i}\right) \mu_{e x}}$

where $D_{h}$ is the hydraulic diameter and $\rho$ is the exhaust gas density. All exhaust gas properties, including thermal conductivity and Prandtl number, were calculated using REFPROP.

The Dittus-Boelter-Correlation for turbulent flow was used for the Nusselt number calculation:

$N u_{e x}=0.023 \operatorname{Re}_{e x}^{0.8} \operatorname{Pr}_{e x}^{0.4}$

With the known tube diameters and the thermal conductivity of exhaust, the heat transfer coefficient of exhaust was ascertained:

$\alpha_{e x}=\frac{N u_{e x} k_{e x}}{D_{0}-D_{i}}$

\subsubsection{Preheater}

Preheating the working fluid up to its evaporation temperature is a vital first step. The individual heat transfer coefficients of the exhaust and the working fluid in the preheater are combined to get the overall heat transfer coefficient for this area:

$U_{\text {preh }}=\frac{1}{\frac{1}{\alpha_{\text {preh }}}+\frac{1}{\alpha_{\text {ex }}}}$

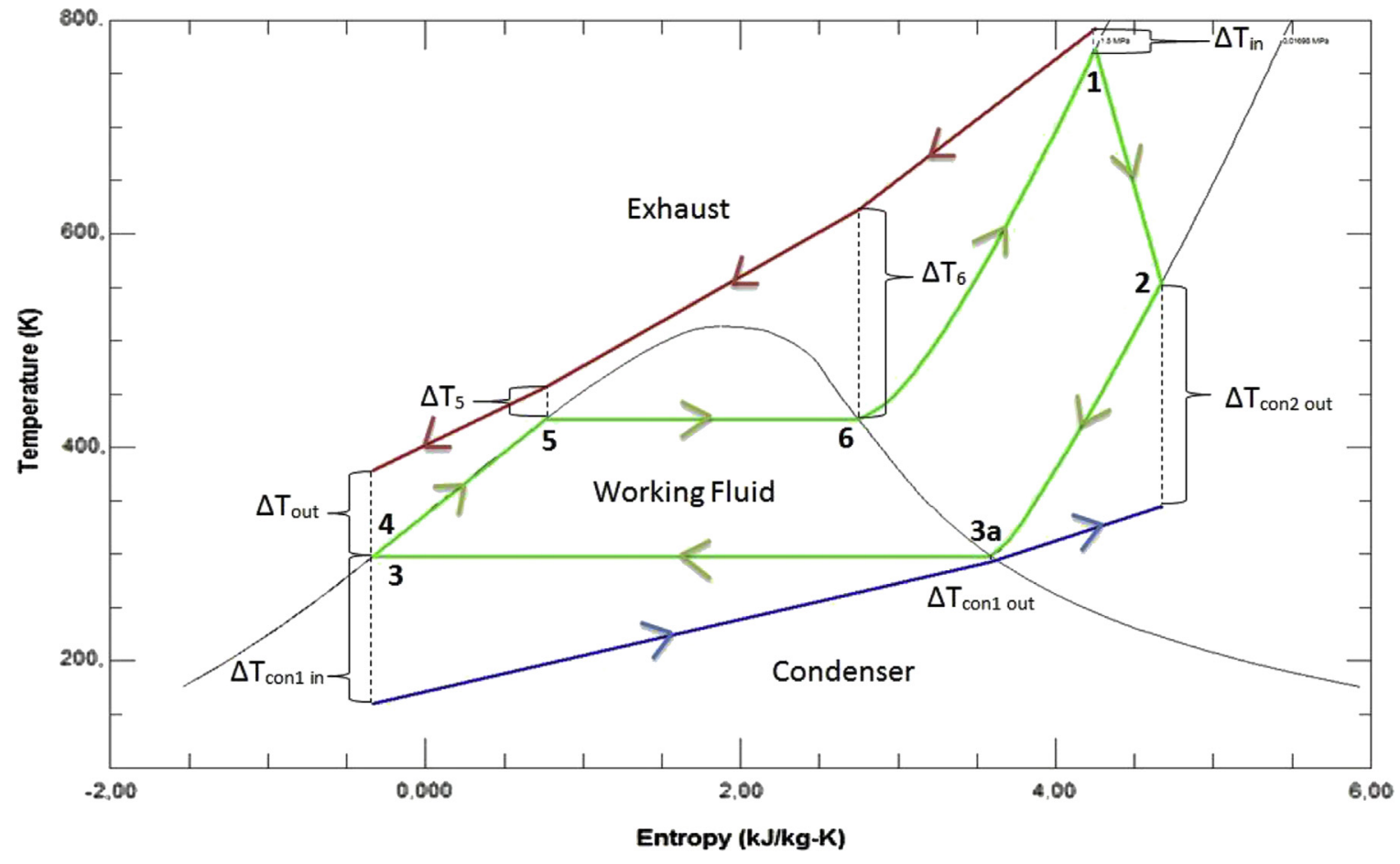

Fig. 3. $T-s$ diagram of the ORC system. 
The heat transfer coefficient for the preheater was calculated using equations (10)-(12), with the appropriate diameter and fluid properties values.

The log mean temperature difference (LMTD) is:

$\Delta T_{\text {lm preh }}=\frac{\Delta T_{5}-\Delta T_{\text {out }}}{\ln \left(\frac{\Delta T_{\text {s }}}{\Delta T_{\text {out }}}\right)}$

The rate of heat flow in the preheater:

$Q_{\text {preh }}=\dot{m}\left(h_{5}-h_{4}\right)$

This allowed us to evaluate the tube length and heat transfer:

$L_{\text {preh }}=\frac{10^{3} Q_{\text {preh }}^{\cdot}}{\pi U_{\text {preh }} D_{i} \Delta T_{\text {lm preh }}}$

$A_{\text {preh }}=\pi L_{\text {preh }} D_{i}$

For a single pressure ratio the preheater heat transfer area decreases with an increase of temperature in point 1 . If the temperature is larger, less preheat area is required as the evaporation temperature is reached at a faster pace.

\subsubsection{Evaporator}

The heat transfer area calculations for the preheater and superheater are relatively similar, as these heat exchangers operate without the phase change. The evaporator analysis requires different and more detailed calculations. In out model, we have used Chen Correlation to determine all mandatory parameters [21]. Chen Correlation models the two-phase boiling coefficient, $\alpha_{\text {evap }}$, as the sum of nucleate boiling and convective boiling [22].

$\alpha_{\text {evap }}=\alpha_{n b}+\alpha_{c b}$

There are two general effects influencing the above equation. First, a steep temperature gradient near the tube wall could partially suppress and reduce the nucleate boiling; hence, a suppression factor $S$ is introduced. Secondly, the vapour, which occurs during evaporation, increases liquid velocity and the convective heat transfer; therefore, a multiplier $F$ is introduced as well [22]. Considering these aspects the equation becomes:

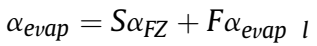

In this case $\alpha_{F Z}$ is given by the Forster and Zuber correlation:

$\alpha_{\mathrm{FZ}}=0.0012 \frac{k_{l}^{0.79} c_{p l}^{0.45} \rho_{l}^{0.49} \Delta T_{\text {sat }}^{0.24} \Delta P_{\text {sat }}^{0.75}}{\sigma^{0.5} \mu_{l}^{0.29} h_{L G}^{0.24} \rho_{g}^{0.24}}$

The thermal conductivity, $k_{l}$, density, $\rho_{l}$, specific heat capacity, $c_{p}$ l, and dynamic viscosity, $\mu_{l}$, of the liquid, and gas density, $\rho_{g}$, were found from REFPROP. Furthermore, the temperature difference $\Delta T_{\text {sat }}$ (the difference between the inner tube wall and the local saturation temperature) was estimated to be $0.5 \mathrm{~K}$. The pressure difference $\Delta P_{\text {sat }}$ (the difference between the pressure at the wall temperature and the pressure at saturation temperature) was evaluated as approximately 0.025 bar. The surface tension, $\sigma$, has almost linear dependence on the temperature and was described using the Eötvös rule:

$\sigma=\frac{k_{e}\left(T_{c}-T_{5}-6\right)}{V_{m}^{2 / 3}}$
The Eötvös constant, $k_{e}$, is $2.1 \times 10^{-7} \mathrm{~J} / \mathrm{Kmol}^{2 / 3}, T_{c}$ is the critical fluid temperature and $V_{m}$ is the molar volume, where $M$ is the molar mass of the fluid:

$V_{m}=\frac{M}{\frac{\rho_{l}+\rho_{g}}{2}}$

The nucleate boiling part of equation (19) requires the suppression factor $S$ :

$S=\frac{1}{1+0.00000253 R_{\text {evap tp }}^{1.17}}$

The Reynolds Number for two-phase evaporator, $R e_{\text {evap } t p}$, is needed, which is a combination of the liquid evaporator Reynolds Number, $R e_{\text {evap l }}$, and the multiplication factor $F$ :

$R e_{\text {evap tp }}=\operatorname{Re}_{\text {evap } l} F^{1.25}$

$F$ is defined as [22]:

$F=\left\{\begin{array}{l}1 \\ 2.35\left(\frac{1}{X_{\text {evap }}}+0.213\right)^{0.736} \frac{\frac{1}{X_{\text {evap }}} \leq 0.1}{\frac{1}{X_{\text {evap }}}>0.1}\end{array}\right.$

where $X_{\text {evap }}$ is the Lockhart-Martinelli parameter, with an assumed vapour quality, $x$, of 0.5 :

$X_{\text {evap }}=\left(\frac{1-x}{\chi}\right)^{0.9}\left(\frac{\rho_{g}}{\rho_{l}}\right)^{0.5}\left(\frac{\mu_{l}}{\mu_{g}}\right)^{0.1}$

The liquid phase heat transfer coefficient has been calculated as [21]:

$\alpha_{\text {evap } l}=0.023 \operatorname{Re}_{\text {evap }}^{0.8} \operatorname{Pr}_{\text {evap }}^{0.4} \frac{k_{l}}{D_{i}}$

Finally, the overall heat transfer coefficient can be determined:

$U_{\text {evap }}=\frac{1}{\frac{1}{\alpha_{\text {evap }}} \frac{D_{o}}{D_{i}}+\frac{1}{\alpha_{\text {ex }}}}$

Alike for the preheater, the LMTD is calculated:

$\Delta T_{\operatorname{lm} \text { evap }} \frac{\Delta T_{6}-\Delta T_{5}}{\ln \left(\frac{\Delta T_{6}}{\Delta T_{5}}\right)}$

Heat flow rate, tube length and the overall evaporator heat transfer area were evaluated as shown above. The evaporator heat transfer area remains almost at the same level for different maximum cycle temperatures. For a constant pressure, the ingoing and outgoing temperatures are always constant as well; only the mass flow rate changes.

\subsubsection{Superheater}

The superheater is a significant part of the cycle, particularly for wet fluids like Methanol. The higher the superheater temperature, the higher the efficiency of the cycle and the risk that the working fluid condenses during the pressure drop inside the turbine, which could lead to corrosion and efficiency drop, is lower. All calculations and principles for the superheater evaluation are the same as previously shown in equations (5)-(17). An increase of the maximum cycle temperature is accompanied by a steeper rise of the superheater heat transfer area. This is consistent with the 
former, as with the higher required maximum temperature more surface area is needed to reach the desired value.

\subsubsection{Air}

Due to its simplicity, non-hazardous and non-toxic nature, we have considered air as the cooling fluid. Evaluation of heat transfer coefficient of air was performed and the heat transfer area of the condensers estimated. The air mass flow rate is assumed as $0.5 \mathrm{~kg} /$ $\mathrm{s} ; \mathrm{Re}, \mathrm{Pr}$ and $\mathrm{Nu}$ numbers and the heat transfer coefficient were calculated as shown above.

\subsubsection{Condenser part 1}

In the first stage condenser, the working fluid undergoes a phase change. A two phase condenser requires, like the evaporator, a more detailed consideration. The inlet temperature and inlet temperature difference are calculated in the same way as for the heat exchangers. For all possible scenarios the conditions

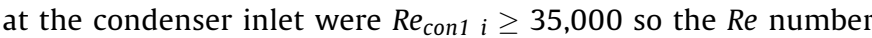
for liquid conditions, with a vapour quality $x$ of 0.5 , are calculated as:

$\operatorname{Re}_{\text {con } 1 l}=\frac{4 \dot{m}(1-x)}{\pi D_{i} \mu_{\text {con } 1} l}$

It is essential to define another Lockhart-Martinelli parameter for the first condenser for $\mathrm{Nu}$ number calculations:

$X_{\text {con } 1}=\left(\frac{1-x}{x}\right)^{0.9}\left(\frac{\rho_{g}}{\rho_{l}}\right)^{0.5}\left(\frac{\mu_{l}}{\mu_{g}}\right)^{0.1}$

$N u_{\text {con } 1}=0.023 R e_{\text {con } 1 l}^{0.8} \operatorname{Pr}_{\text {con } 1 l}^{0.4}\left[1+\frac{2.22}{X_{\text {con } 1}^{0.89}}\right]$

Remaining numerical elements for two phase condenser were evaluated in the same way as for the other heat exchangers. The heat transfer area of the first condenser is practically the same for each cycle. The only part which differs is the mass flow rate, but the temperatures are constant in all cases.

\subsubsection{Condenser part 2}

The second condenser is the part which serves to cool the fluid down to the condensing temperature after it leaves the turbine. This heat exchanger has the same operational concept as the preheater and the superheater, but with reversed direction of the heat flow; hence the same set of equations was used. Whereas the outgoing turbine temperature increases with a rising maximum cycle temperature, the heat transfer area increases slightly as well. To get a sufficient comparison between all different cycles, all previously calculated heat transfer areas should be summed up:

$\Sigma A_{\text {all }}=\Sigma A_{\text {heater }}+\Sigma A_{\text {con }}=A_{\text {preh }}+A_{\text {evap }}+A_{\text {sup }}+A_{\text {con } 1}+A_{\text {con } 2}$

\section{Results and discussion}

\subsection{Thermal efficiency}

Thermal efficiency was evaluated for each cycle and all high cycle pressure and maximum cycle temperature variations, depending on the type of working fluid. Fig. 4 shows the thermal efficiency of a Methanol ORC with a turbine inlet temperature ranging between $150{ }^{\circ} \mathrm{C}$ and $500{ }^{\circ} \mathrm{C}$ and the high pressures between 1 and 20 bar. For a set pressure level, thermal efficiency increases almost linearly with temperature; the gradient is steeper for higher pressures. More prominent, exponential rise in efficiency is seen when the high cycle pressure grows. This is expected behaviour of a wet fluid and the cycle efficiency at greater pressures is additionally augmented by the temperature increase. Problems could occur at low temperature and high pressure combinations. Methanol starts to expand into the area of wet steam, resulting in efficiency and power losses. Superheating is vital to obtain high efficiencies and net power output and to avoid a wet expansion. The highest efficiency is found for the maximum temperature and pressure $-24.1 \%$.

The efficiency of Toluene cycles shows different behaviour in comparison to Methanol (Fig. 5). While both fluids achieve better performance at higher pressures, for a set pressure value the cycle

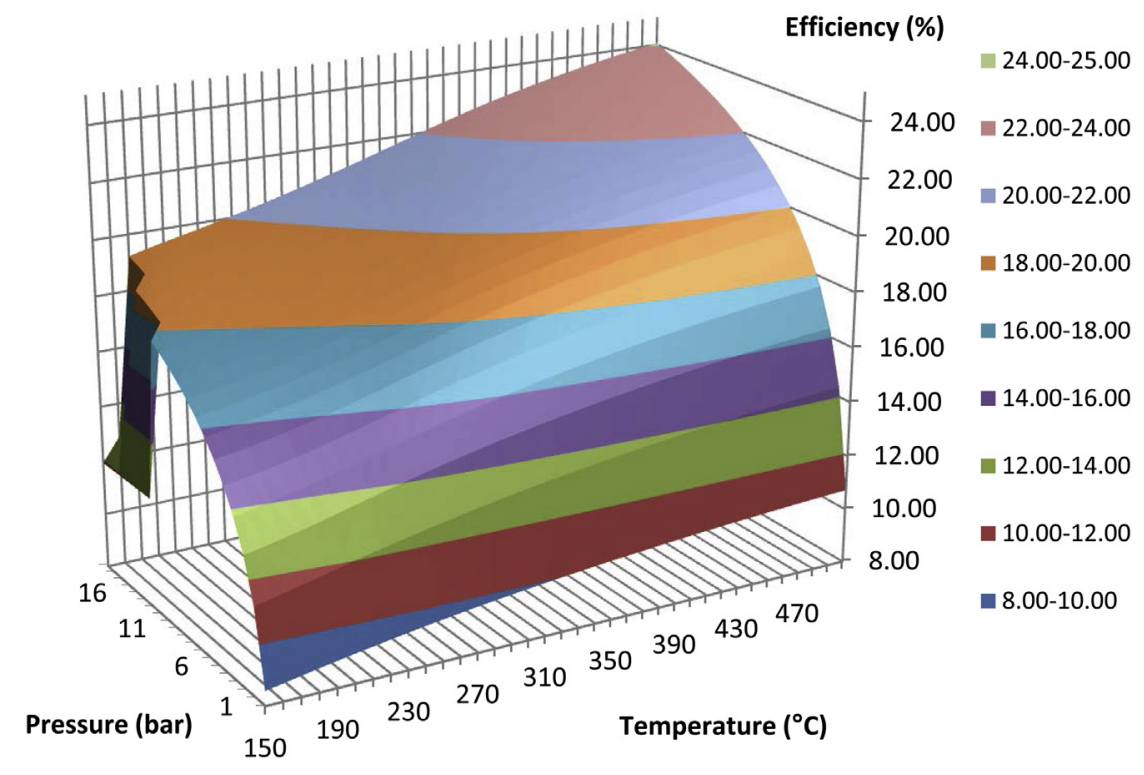

Fig. 4. 3D thermal efficiency diagram for Methanol cycle. 
efficiency decreases with the rise of the turbine inlet temperature. Efficiencies of Toluene ORC were generally lower than those of Methanol cycles for higher temperature values; conversely Toluene performed better with intermediate temperature heat inputs, confirming fluid selection practice has to take in account the magnitude of heat available in order to ensure the best possible performance.

Moreover, at the lowest investigated temperature and high pressures the efficiency is found to be considerably lower than the efficiencies around this area. Toluene is a dry fluid, therefore there is no risk as for Methanol that the fluid becomes liquid during the expansion inside the turbine. Yet, the combination of high pressure and low temperature imposes a risk that the fluid is not thoroughly vaporised at the turbine inlet. This entails as a consequence that the efficiency drops at this point and there is a risk of corrosion inside the turbine. The "cut-off point for this phenomenon was found to be at 17 bar and $250^{\circ} \mathrm{C}$. However, the maximum thermal efficiency of $22.1 \%$ was found at $270{ }^{\circ} \mathrm{C}$ and 20 bar. In comparison, at 10 bar Methanol efficiency ranges from $18.3 \%$ to $21.5 \%$, while for the same operating pressure Toluene reaches $20.6 \%$ as a maximum efficiency. Dry fluids are well suited for ORCs, yet when a high-temperature fluid like Toluene is employed sufficient heat input is required to ensure complete vaporisation.

Only high cycle temperatures lower than $220^{\circ} \mathrm{C}$ were taken in account in Solkatherm cycles, as the working fluid starts decomposing above this temperature. Solkatherm had lower efficiency compared to Methanol and Toluene. As it can be seen in Fig. 6 this mixture resembles a dry fluid. Therefore, at low pressures diagram has a comparable shape to Toluene cycles, while the evaluated thermal efficiency was a mere third of those achieved by Methanol and Toluene. Nevertheless, it is intriguing that for very low pressures the efficiency remains virtually constant despite the temperature increase. This diagram is unique to the extent that the development of the efficiency is only a function of pressure. Since temperature influence seems to be irrelevant, Solkatherm has vast potential to be utilised in applications where variations in magnitude of heat input are expected. Yet, in order to achieve greater cycle efficiency relatively high pressures are necessary, which may prove to be problematic. Again, as a typical dry fluid it prefers a modest maximal temperature level.

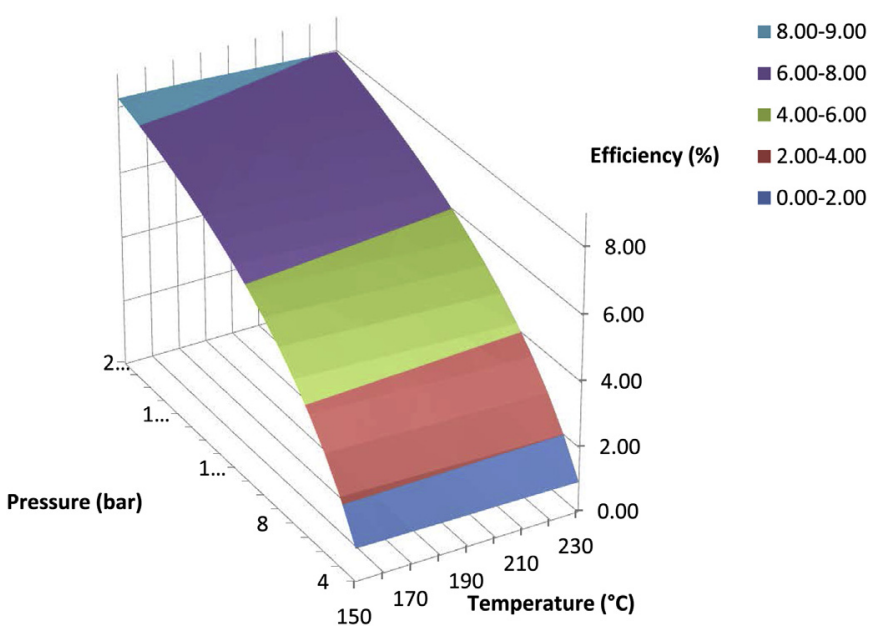

Fig. 6. 3D thermal efficiency diagram for Solkatherm cycle.

\subsection{Net power output}

Net power produced by Methanol ORC is presented in Fig. 7. Especially for low pressure cycles the shape of the net power output diagram is approximately the same like the corresponding efficiency diagram. Consequently, the net power output for low pressure cycles for Methanol increases with the turbine inlet temperature. Based on the estimated flow rate of $0.057 \mathrm{~kg} / \mathrm{s}$ the maximum achievable power output is $28.7 \mathrm{~kW}$.

The Toluene diagram for net power output (Fig. 8) has an analogical similarity to Fig. 5. However, the rate of increase of net power output at higher pressures and low temperatures is greater. The maximum net power output for Toluene is higher than for Methanol. The same net power produced by Methanol ORC at maximum temperature and pressure is achievable by Toluene ORC operating at around 5 bar and $250{ }^{\circ} \mathrm{C}$ up to 20 bar and $380^{\circ} \mathrm{C}$, but for higher pressures Toluene is not as stable. Toluene generates higher output rates with further increase in pressure and reduction in temperature, but for pressures above 17 bar and temperature of

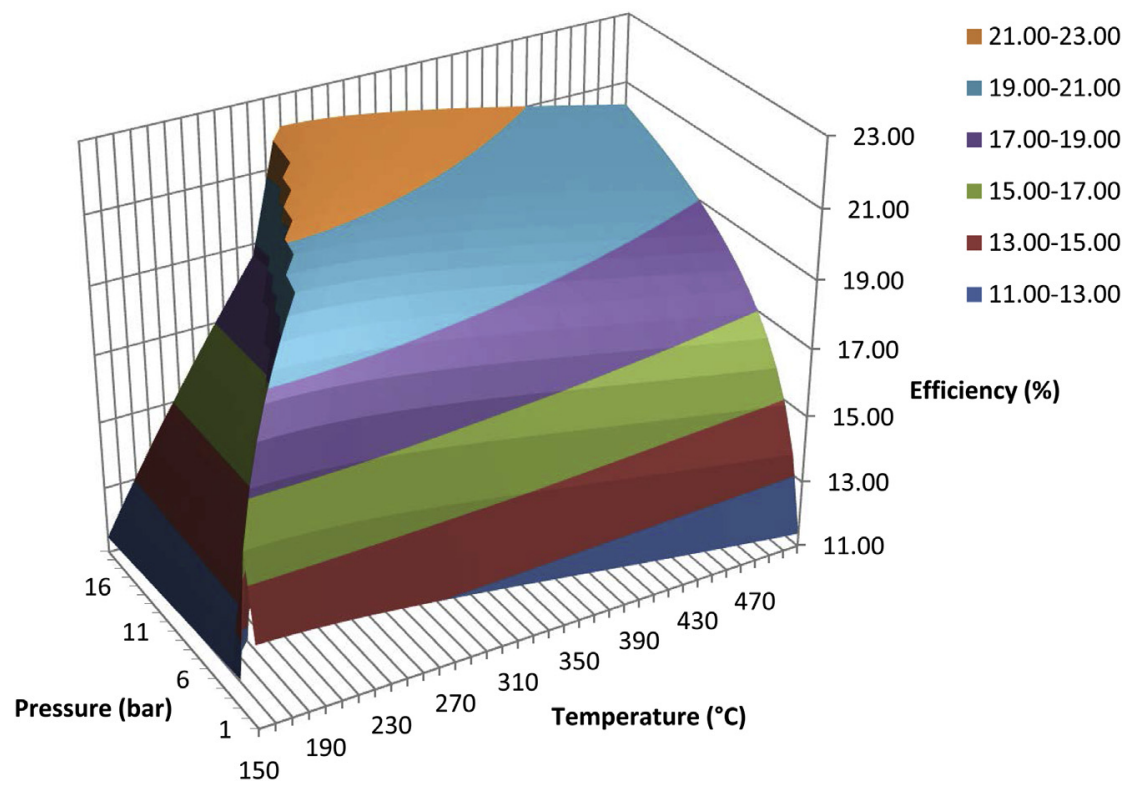

Fig. 5. 3D thermal efficiency diagram for Toluene cycle. 


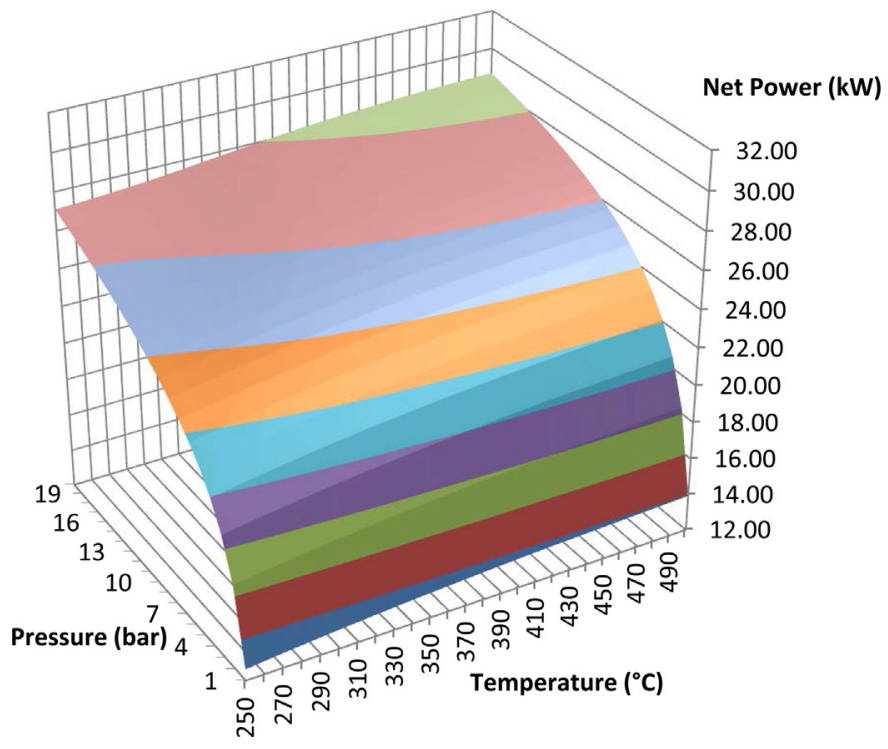

$-30.00-32.00$
$-28.00-30.00$
$-26.00-28.00$
$-24.00-26.00$
$\square 22.00-24.00$
$-20.00-22.00$
$-18.00-20.00$
$-16.00-18.00$
$\square 14.00-16.00$
$\square 12.00-14.00$

Fig. 7. 3D net power output diagram for Methanol cycle.

$250{ }^{\circ} \mathrm{C}$ the output drops abruptly. This occurs due to incomplete evaporation at the turbine inlet. It should be guaranteed that Toluene is entirely evaporated in order to avoid this undesirable behaviour.

Fig. 9 reveals similar trends as seen for thermal efficiency variation of Solkatherm low pressure cycles. The maximum net power output was achieved through high pressure and low temperature combination, which is roughly the half of the maximum net work found for Methanol. While clearly Solkatherm is not an ideal candidate for highly efficient ORC, given the poor thermal performance, its net power is substantial, and unlike Toluene ORC it is fully superheated at high pressures even at very low temperatures.

\subsection{Heat transfer area}

Our analysis includes the evaluation of heat transfer area for the appropriate heat exchanger. It takes in account all heat exchangers elements; the calculated areas are those required for predefined temperatures to be reached.

For Methanol cycles the total heat transfer area simply grows with the increasing pressure. For the lowest pressures the heat transfer area increases with a rising temperature, whereas for high pressure the curve takes a more parabolic shape (Fig. 10). The area is high for the lowest and the highest investigated temperatures and has its minimal turning point in the intermediate temperature range.

The higher the defined ingoing maximum temperature, the higher the heat transfer area of the superheater, hence this area increases with the temperature. On the other hand, the heat transfer area of the preheater decreases with increasing temperature; the area of evaporator remains almost on the same level. For low pressure cycles the average heat transfer area for the preheater is relatively low; thus, it does not affect the overall heat transfer area significantly. With a pressure increase the average area of the

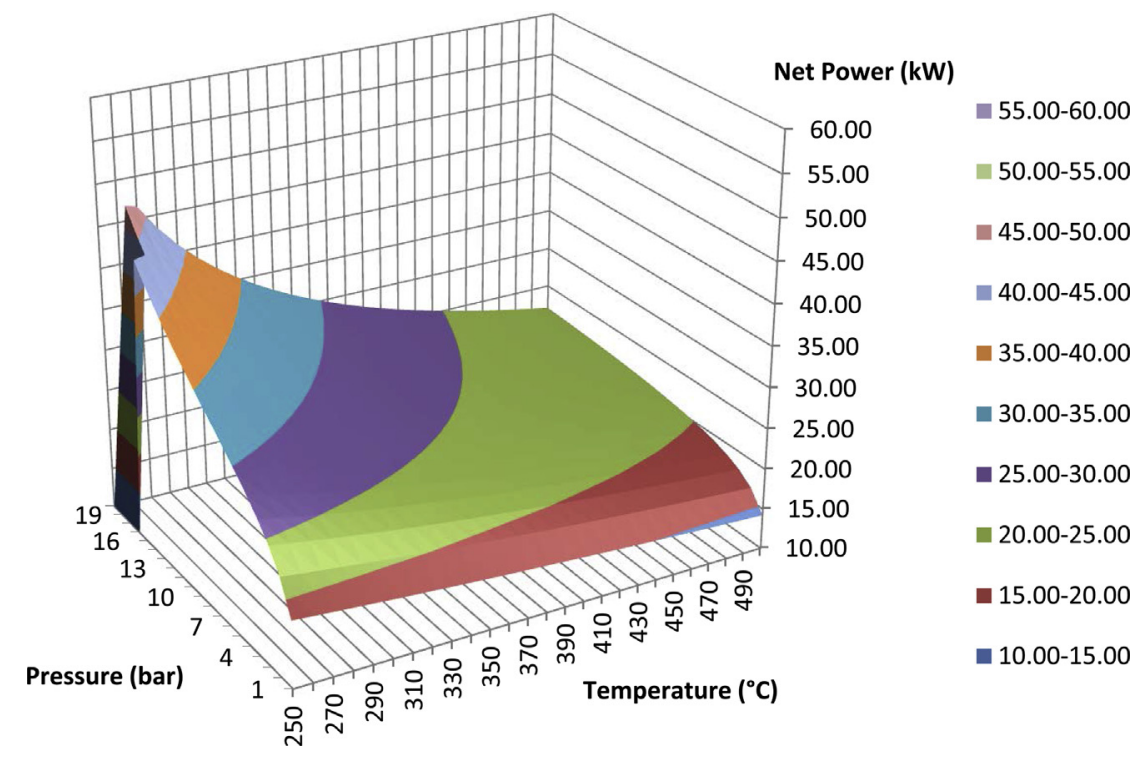

Fig. 8. 3D net power output diagram for Toluene cycle. 


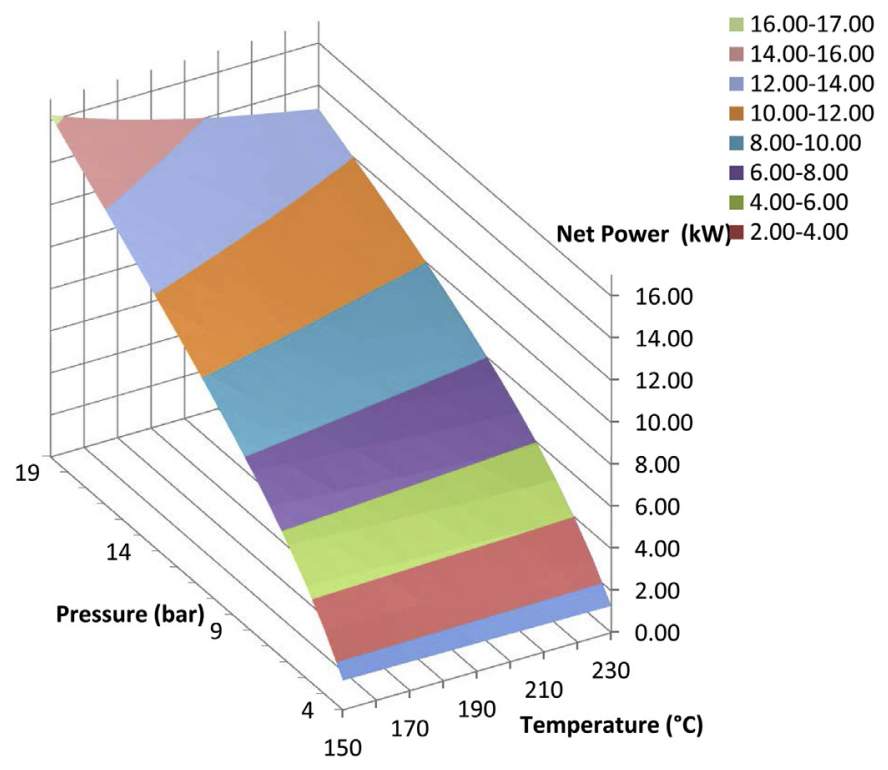

Fig. 9. 3D net power output diagram for Solkatherm cycle.

preheater becomes important. $\mathrm{T}-\mathrm{Q}$ diagram for the primary heat exchanger is given in Fig. 12. High pressures increase heating load of the preheater, while for the set temperature net heat input in the superheater is relatively constant. Consequently, share of the heating load of the evaporator decreases.

An acceptable compromise between heat transfer area, net power output and the efficiency needs to be found. The best thermal performance of Methanol is at the maximum investigated temperature and pressure, but this is also the highest evaluated heat transfer area. At this point the efficiency is $24.1 \%$ and the net power output is $28.7 \mathrm{~kW}$; however, this requires the heat transfer area of $1.64 \mathrm{~m}^{2}$. An acceptable solution would be to keep the pressure high, but to consider temperature range between $360{ }^{\circ} \mathrm{C}$ and $410{ }^{\circ} \mathrm{C}$. Under these conditions the heat transfer area is smaller $\left(1.44 \mathrm{~m}^{2}\right)$, but the efficiency and net power output are still relatively high, $22-23 \%$, and $28-28.4 \mathrm{~kW}$, respectively.
The heat transfer area of Toluene yet again exhibits a different trend compared to Methanol. Similarly to the efficiency and net power output, the heat transfer area of Toluene is relatively unstable for high pressures and low temperatures. Toluene cycle has sensible heat transfer area between $1.6 \mathrm{~m}^{2}$ and $1.8 \mathrm{~m}^{2}$. Trends on Fig. 11 reveal ideal temperature input is between $440^{\circ} \mathrm{C}$ and $470^{\circ} \mathrm{C}$. However, the pressure would need to be relatively high, between 17 bar and 20 bar. At this range of parameters, Toluene ORC achieved a thermal efficiency between $20.2 \%$ and $21 \%$, and a net power output between $23 \mathrm{~kW}$ and $24.8 \mathrm{~kW}$.

Quantitative comparison reveals a number of advantages of Methanol ORC over Toluene one. While Toluene performs remarkably well at high-temperature inputs in terms of the net power produced, higher efficiencies and smaller heat transfer area make Methanol a more attractive candidate. While no fluid is perfect [12], a good match must be found between the fluid and the operating pressures and temperatures. The efficiency and net power output had the highest values for high pressures; thus 20 bar presents itself as the optimum pressure - a realistic parameter, which can be successfully and safely implemented. Once a high pressure is reached the Methanol ORC net power output increases only slightly with the temperature. The efficiency increases more with the temperature, but the high pressure is a more influential parameter. The heat transfer area, and therefore the heat exchanger size, exhibits a minimum at intermediate temperatures.

The heat exchanger size is vital as it affects the weight of the overall system, and a relatively high turbine inlet temperature, between $360{ }^{\circ} \mathrm{C}$ and $410{ }^{\circ} \mathrm{C}$, should be the best solution. While Methanol is a remarkably stable compound, decomposition is likely to occur at these conditions; therefore, an intermediate temperature range may be a more appropriate. The required size of the heat transfer area increases from its minimum value with decreasing temperature, yet less so for lower pressures. Namely, Methanol ORC operating between $310^{\circ}$ and $350{ }^{\circ} \mathrm{C}$ at 18 bar would require a similar heat exchanger size. These operating conditions would impose up to $2 \mathrm{~kW}$ reduction in net power output and less than $2 \%$ loss in thermal efficiency. A heat exchanger of comparable size for Toluene ORC would operate at very low pressures, and achieved power and thermal efficiency would be particularly low.

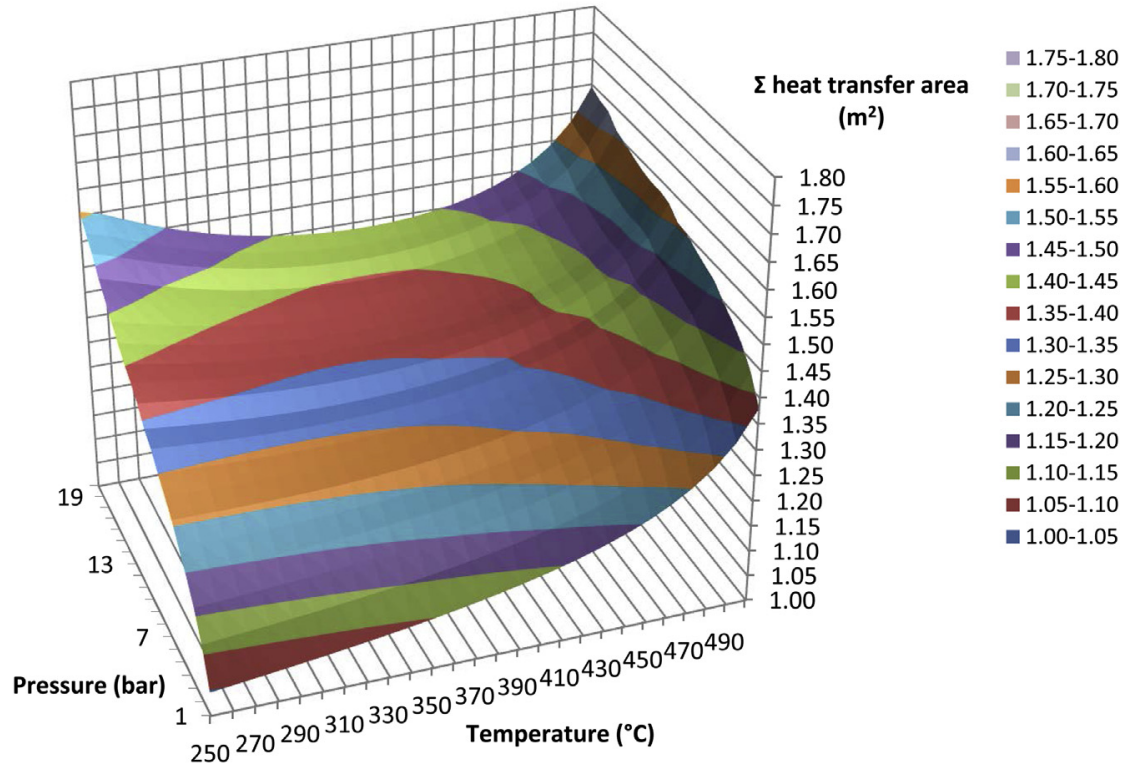

Fig. 10. 3D diagram of the overall heat transfer area for Methanol cycle. 


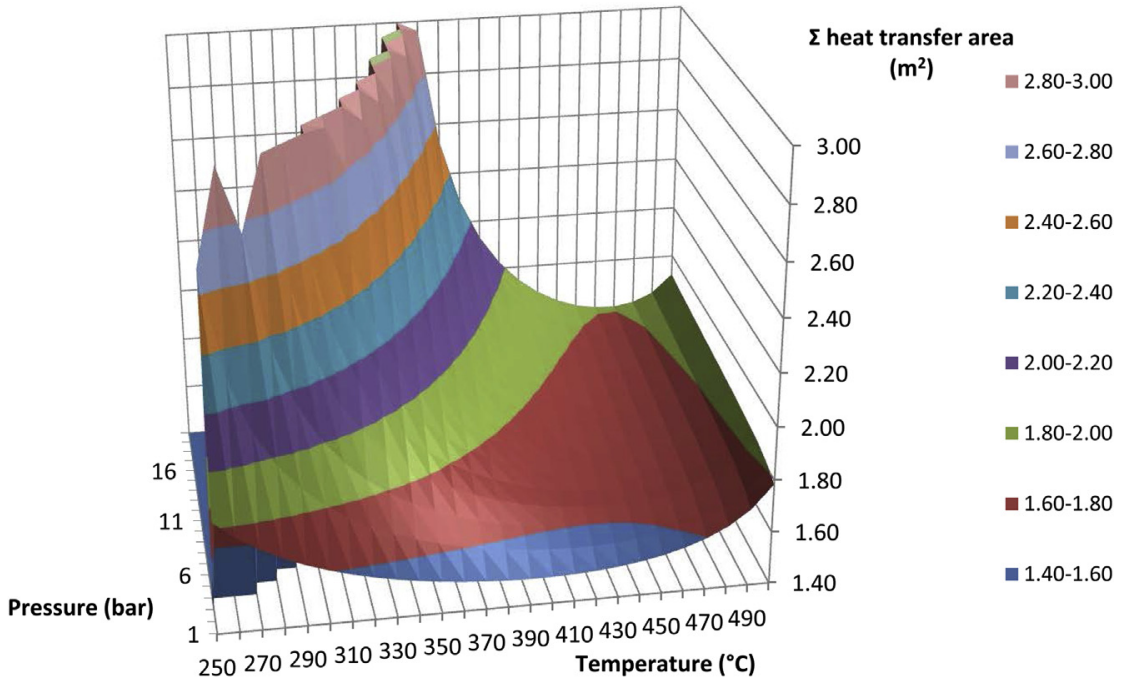

Fig. 11. 3D diagram of the overall heat transfer area for Toluene cycle.

In summary, Methanol cycle with a maximum pressure of 18 bar and turbine inlet temperature $320^{\circ} \mathrm{C}$ is a good compromise between heat exchanger dimensional requirements and operating parameters needed for desired thermodynamic performance. Intermediate range of temperatures selected is manageable and should ensure safe and controlled cycle operation. It should be mentioned there are certain risks associated with the use of Methanol as a working fluid, due to its flammability issues. While it is not uncommon for high flammability working fluids to be considered for ORC operation, it is crucial to perform in-depth evaluation of the associated risks [10,23]. With high auto-ignition temperature and remarkable chemical stability, as well as from the economical point of view, Methanol has a potential to be a good ORC working fluid.

\section{Conclusion}

In this work the thermodynamic behaviour of Methanol, Toluene and Solkatherm SES36 has been investigated. Numerical tools have been developed to determine the thermal efficiency, net power output and the overall heat transfer area. While all calculations were carried out under steady-state steady flow conditions,

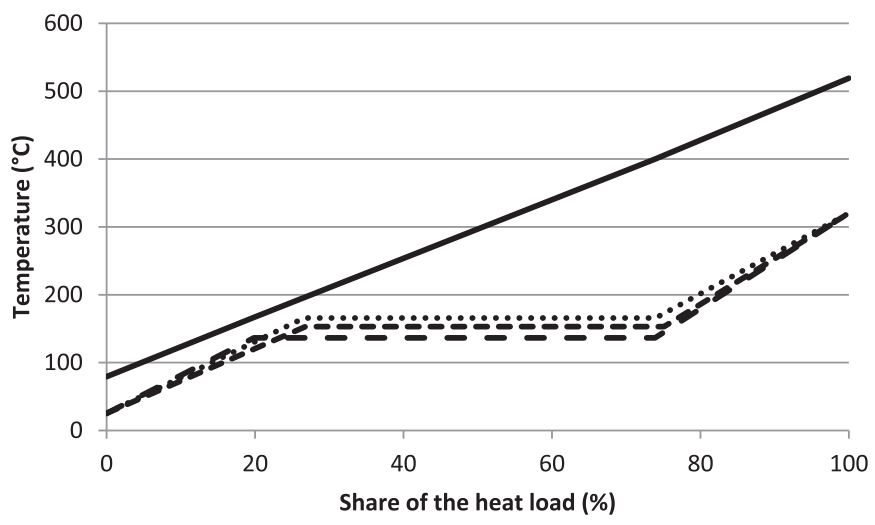

Fig. 12. $T-Q$ plane for the primary heat exchanger for Methanol ORC cycle: high cycle temperature $320^{\circ} \mathrm{C}$ and high cycle pressure 10 bar (long dashed line); 15 bar (short dashed line); 20 bar (dotted line); exhaust stream (solid line). our method depicted the effect of distinctive fluid characteristics on the cycle performance.

Although Toluene had the highest net power output, Methanol was chosen as a better suited fluid. Methanol ORC was more stable than Toluene and had higher average thermal efficiency. With Toluene a great amount of work can be produced, but it is not unaffected by small changes in temperature or pressure. These fluctuations could lead to a total net power output loss. Solkatherm had by far the lowest efficiency and net power output. Heat transfer area of Methanol cycle is sensible and from both thermodynamic and economical point of view was proved to be a good working fluid.

\section{References}

[1] M. Tahani, S. Javan, M. Biglari, A comprehensive study on waste heat recovery from internal combustion engines using Organic Rankine Cycle, Therm. Sci. 17 (2) (2013) 611-624.

[2] V. Dolz, et al., HD diesel engine equipped with a bottoming Rankine cycle as a waste heat recovery system. Part 1: study and analysis of the waste heat energy, Appl. Therm. Eng. 36 (0) (2012) 269-278.

[3] S.N. Hossain, S. Bari, Waste heat recovery from the exhaust of a diesel generator using Rankine Cycle, Energy Convers. Manag. 75 (0) (2013) $141-151$.

[4] S. Quoilin, et al., Techno-economic survey of Organic Rankine Cycle (ORC) systems, Renew. Sustain. Energy Rev. 22 (0) (2013) 168-186.

[5] U. Larsen, et al., Design and optimisation of Organic Rankine Cycles for waste heat recovery in marine applications using the principles of natural selection, Energy 55 (0) (2013) 803-812.

[6] G. Yu, et al., Simulation and thermodynamic analysis of a bottoming Organic Rankine Cycle (ORC) of diesel engine (DE), Energy 51 (0) (2013) 281-290.

[7] C.O. Katsanos, D.T. Hountalas, E.G. Pariotis, Thermodynamic analysis of a Rankine Cycle applied on a diesel truck engine using steam and organic medium, Energy Convers. Manag. 60 (0) (2012) 68-76.

[8] R. Capata, C. Toro, Feasibility analysis of a small-scale ORC energy recovery system for vehicular application, Energy Convers. Manag. 86 (0) (2014) 1078-1090.

[9] B.F. Tchanche, et al., Low-grade heat conversion into power using Organic Rankine Cycles - a review of various applications, Renew. Sustain. Energy Rev. 15 (8) (2011) 3963-3979.

[10] D. Maraver, et al., Systematic optimization of subcritical and transcritical Organic Rankine Cycles (ORCs) constrained by technical parameters in multiple applications, Appl. Energy 117 (0) (2014) 11-29.

[11] M.A. Siddiqi, B. Atakan, Investigation of the Criteria for fluid selection in Rankine Cycles for waste heat recovery, Atık Isı Gerikazanımı için Rankine Çevriminde Akışkan Seçimi Kriterinin İncelenmesi 14 (3) (2011) 117-123.

[12] J.J. Bao, L. Zhao, A review of working fluid and expander selections for Organic Rankine Cycle, Renew. Sustain. Energy Rev. 24 (2013) 325-342.

[13] C.M. Invernizzi, Closed Power Cycles: Thermodynamic Fundamentals and Applications. Lecture Notes in Energy, Springer, 2013. 
[14] H. Madani, A. Valtz, C. Coquelet, Isothermal vapor-liquid equilibrium data for the decafluorobutane (R3110) + 1,1,1,3,3-pentafluorobutane (R365mfc) system at temperatures from $333 \mathrm{~K}$ to $441 \mathrm{~K}$, Fluid Phase Equilibria (2013) 109.

[15] C.V. Jakeways, A.R.H. Goodwin, The viscosity and density of 1propene,1,1,2,3,3,3-hexafluoro- oxidized,polymd and polydimethylsiloxane at temperatures from (313 to 373 ) K and a pressure of $0.1 \mathrm{MPa}$, J. Chem. Thermodyn. 37 (10) (2005) 1093-1097.

[16] C. He, et al., The optimal evaporation temperature and working fluids for subcritical Organic Rankine Cycle, Energy 38 (1) (2012) 136-143.

[17] H. Tian, et al., Fluids and parameters optimization for the Organic Rankine Cycles (ORCs) used in exhaust heat recovery of Internal Combustion Engine (ICE), Energy 47 (1) (2012) 125-136.

[18] C. Günter, W. Gernot, Der Dampf und seine Anwendung in Maschinen und Anlagen, in: Technische Thermodynamik, Carl Hanser Verlag GmbH \& Co. KG, 2013, pp. 223-290.
[19] C. Guo, et al., Performance analysis of Organic Rankine Cycle based on location of heat transfer pinch point in evaporator, Appl. Therm. Eng. 62 (1) (2014) 176-186.

[20] National Institute of Standards and Technology (NIST), NIST Reference Fluid Thermodynamic and Transport Properties Database (REFPROP), 2014 Gaithersburg.

[21] J. Navarro-Esbrí, et al., Shell-and-tube evaporator model performance with different two-phase flow heat transfer correlations. Experimental analysis using R134a and R1234yf, Appl. Therm. Eng. 62 (1) (2014) 80-89.

[22] J.R. Thome, Wolverine Engineering data Book III, Heat Transf. Eng. 26 (1) (2005), 60-60.

[23] R.A. Victor, J.-K. Kim, R. Smith, Composition optimisation of working fluids for Organic Rankine Cycles and Kalina cycles, Energy 55 (0) (2013) $114-126$. 